\title{
Safety and Effectiveness of Switching from a Basal- only to Biphasic Insulin Aspart 30 Insulin Regimen
}

\author{
Jihad Haddad $\cdot$ Mohsen Khoshniatnikoo $\cdot$ \\ Youcef Benabbas · Serdar Guler • \\ Vinay Prusty $\cdot$ Pradana Soewondo
}

To view enhanced content go to www.diabetestherapy-open.com

Received: May 1, 2013 / Published online: July 12, 2013

(C) The Author(s) 2013. This article is published with open access at Springerlink.com

\section{ABSTRACT}

Purpose: This sub-analysis of the $\mathrm{A}_{1}$ chieve study evaluated the safety and effectiveness of changing from a basal-only insulin regimen to biphasic insulin aspart 30.

Methods: $\mathrm{A}_{1}$ chieve was an international, multicenter, prospective, open-label, noninterventional, 24-week study in people with type 2 diabetes mellitus starting/switching to therapy with biphasic insulin aspart 30, insulin detemir, or insulin aspart (alone/in combination) in routine clinical practice. This

J. Haddad

Endocrinology Section, Department of Internal

Medicine, Prince Hamzah Hospital, Amman, Jordan

M. Khoshniatnikoo

Endocrinology and Metabolism Research Institute,

Tehran University of Medical Sciences, Tehran, Iran

Y. Benabbas

Department of Internal Medicine, University

Hospital of Constantine, Constantine, Algeria

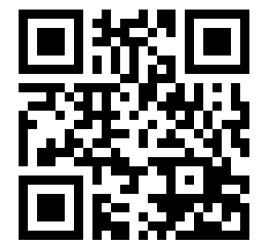

Enhanced content for this article is

available on the journal web site:

www.diabetestherapy-open.com sub-analysis evaluated the safety and effectiveness of switching from basal insulin with either insulin glargine (GLA group) or insulin neutral protamine Hagedorn (NEU group) to biphasic insulin aspart 30 .

Results: A total of 2,818 participants received biphasic insulin aspart 30 (1,395 in the GLA group and 1,423 in the NEU group). After 24 weeks of treatment, there were significant reductions in the proportion of patients with at least one hypoglycemia event: total [baseline vs. 24 weeks: $15.5 \%$ vs. $9.7 \%(p<0.001)$ and $12.3 \%$ vs. $9.9 \%(p<0.05)$, in NEU and GLA groups, respectively], major $[2.5 \%$ vs. $0.08 \%(p<0.001)$

\footnotetext{
S. Guler

Ankara Numune Training and Research Hospital, Sihhiye, 06100 Ankara, Turkey
}

\section{Prusty ( $\square)$}

Novo Nordisk Region International Operations A/S, Andreasstrasse 15, 8050 Zurich Oerlikon, Switzerland

e-mail: vpru@novonordisk.com

\section{P. Soewondo}

Division of Endocrinology and Metabolism, Department of Internal Medicine, Faculty of Medicine, University of Indonesia, Jakarta, Indonesia 
and $1.2 \%$ vs. $0.08 \%(p<0.001)$, in NEU and GLA groups, respectively] and nocturnal hypoglycemia $[7.2 \%$ vs. $3.5 \%(p<0.001)$ and $5.4 \%$ vs. $3.9 \%(p<0.05)$, in NEU and GLA groups, respectively]. After 24 weeks of biphasic insulin aspart 30 there were statistically significant improvements from baseline in glycated hemoglobin, fasting plasma glucose, and post-prandial plasma glucose levels $(p<0.001)$ and in health-related quality of life $(p<0.001)$ in both groups.

Conclusions: Biphasic insulin aspart 30 may benefit patients with poor glycemic control on basal insulin regimens who are seeking to change treatment.

Keywords: $\mathrm{A}_{1}$ chieve; Basal insulin; Biphasic insulin aspart 30; Effectiveness; Type 2 diabetes mellitus

\section{INTRODUCTION}

People with type 2 diabetes who fail to attain optimal glycemic control while receiving oral glucose-lowering drugs (OGLDs) are frequently prescribed basal insulin [1]. However, there is a requirement for treatment regimens to be continually assessed, because as disease progresses it may be necessary to intensify treatment to maintain glycemic control within accepted targets [1]. One option for intensifying treatment may be to switch patients from basal insulin to premixed insulin, which contains basal plus rapid-acting insulin in one injection. There are currently few data to describe how effective premixed insulins may be in people with type 2 diabetes who are failing to maintain glycemic control on basal insulin [1]. However, meta-analyses and systematic reviews of published clinical trials indicate that premixed insulin treatment may have benefits over basal insulin treatment in enabling patients to reach glycemic targets [2, 3].

Interventional studies have demonstrated that targeting raised post-prandial plasma glucose (PPG) hyperglycemia is essential in reducing elevated glycated hemoglobin $\left(\mathrm{HbA}_{1 \mathrm{c}}\right)$ to accepted target levels [4]. Indeed, previous studies have demonstrated a strong correlation between elevated PPG levels and the risk of developing diabetes complications [4-7]. In type 2 diabetes, basal insulins such as insulin glargine and neutral protamine Hagedorn (NPH) insulin are effective for basal control of glucose, but do not target PPG fluctuations [8, 9]. Insulin regimens that can reduce PPG fluctuations, such as, biphasic insulin aspart 30, may be beneficial in some clinical situations, such as when basalonly insulin regimens are failing to control blood glucose levels [10].

$\mathrm{A}_{1}$ chieve was an international noninterventional study evaluating the safety and clinical effectiveness of insulin regimens in patients with type 2 diabetes receiving routine clinical care in 28 countries across 4 continents [11]. The full results of the $A_{1}$ chieve study have been published [11], but it is interesting to look at specific sub-groups of this large observational study to gain information on the potential benefits of specific insulin regimens or switches to new insulin regimens. The purpose of this sub-analysis was to evaluate the safety and effectiveness of switching people with type 2 diabetes from a basal only insulin \pm OGLDs regimen to a biphasic insulin aspart $30 \pm$ OGLDs regimen.

\section{METHODS}

$\mathrm{A}_{1}$ chieve was a prospective, international, multicenter, open-label, non-interventional, 24-week study in people with type 2 diabetes 
in routine clinical practice who were being treated with anti-diabetes medication before starting, or switching to, insulin therapy with biphasic insulin aspart 30 (NovoMix ${ }^{\circledR}$; Novo Nordisk A/S, Bagsvaerd, Denmark), insulin

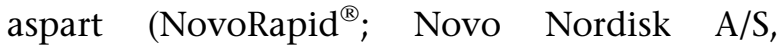
Bagsvaerd, Denmark), or insulin detemir (Levemir $^{\circledR}$; Novo Nordisk A/S, Bagsvaerd, Denmark) either in conjunction with or without OGLDs [11]. All study participants signed informed consent forms and were free to withdraw from the study at any time. The study was conducted in accordance with the Declaration of Helsinki of 1964, as revised in 2008 [12], and guidelines for good pharmacoepidemiology practice [13].

Clinic visits were defined as baseline, interim [approximately 12 weeks from baseline (results not reported here)], and a final visit (approximately 24 weeks from baseline).

The primary objective of this sub-analysis was to evaluate the safety profile of switching from a basal-only insulin regimen to insulin therapy with biphasic insulin aspart 30 by measuring the incidence of serious adverse drug reactions (SADRs), including major hypoglycemia events. Other safety assessments included the change in the number of overall, major, or nocturnal hypoglycemia events between baseline and 24 weeks. These were based on patient recall of events within the last 4 weeks before the study visit.

A hypoglycemia event was defined as an event with symptoms of hypoglycemia that resolved with glucagon, oral carbohydrate intake, or intravenous glucose, or any symptomatic or asymptomatic event where plasma glucose was $<3.1 \mathrm{mmol} / \mathrm{l}$ or $<56 \mathrm{mg} / \mathrm{dl}$. Major hypoglycemia events were defined as events with severe central nervous system symptoms consistent with hypoglycemia, in which the patient was unable to self-treat and had one of the following characteristics: plasma glucose $<3.1 \mathrm{mmol} / \mathrm{l}$ or $<56 \mathrm{mg} / \mathrm{dl}$, or reversal of symptoms after either food intake, glucagon or intravenous glucose administration. Nocturnal hypoglycemia events were defined as individualized symptomatic events consistent with hypoglycemia, which occurred between bedtime after the evening insulin injection and before getting up in the morning; if applicable, events were those that occurred before morning determination of fasting plasma glucose (FPG) and the morning insulin injection.

Secondary endpoints included the change in glycated hemoglobin, FPG levels before breakfast, PPG levels after breakfast, after lunch and after dinner, body weight, systolic blood pressure, and health-related quality of life (HRQoL) between baseline and 24 weeks. HRQoL was self-assessed at baseline and after 24 weeks by the patients using the EuroQol (EQ5D) a standardized questionnaire for use as a measure of health outcome. The EQ-5D provides a single index value for status of health, and evaluates five domains of patient health/lifestyle (mobility, self-care, usual activities, pain/discomfort, and anxiety/ depression). Patient responses were evaluated on a visual analogue scale (VAS) of 0 (worst imaginable health) to 100 (best imaginable health). The dosage of basal insulin before switching to biphasic insulin aspart 30, the dosage of biphasic insulin aspart 30 at initiation, and the dosage of biphasic insulin aspart 30 administered at subsequent visits were recorded.

\section{Statistical Analysis}

This publication reports the results for patients who were receiving basal insulin regimens with insulin glargine (GLA group) or neutral protamine Hagedorn (NPH; NEU group) at pre-study visit and 
were switched to biphasic insulin aspart 30 ( \pm OGLDs) in the $A_{1}$ chieve study. Analysis of each of the safety and effectiveness outcome measures was performed by pre-study basal insulin experience (insulin glargine or NPH insulin).

Analyses were performed on the full analysis set, defined as all patients with a baseline visit and who received at least one dosage of biphasic insulin aspart 30. McNemar's test was used to analyze the proportion of patients reporting at least one hypoglycemia event. The number of SADRs considered to be related to biphasic insulin aspart 30 was also recorded. Changes from baseline in $\mathrm{HbA}_{1 \mathrm{c}}, \mathrm{FPG}, \mathrm{PPG}$, systolic blood pressure, body weight, and HRQoL were analyzed using paired $t$ test. All statistical tests were two-tailed, using a 5\% significance level, and were conducted by Novo Nordisk A/S using SAS $^{\circledR}$ Version 9.1.3 (SAS $^{\circledR}$ Institute Inc., Cary, NC, USA).

\section{RESULTS}

\section{Study Participants}

A total of 2,818/66,726 (4.2\%) participants were switched to biphasic insulin aspart 30 at baseline: 1,395/66,726 (2.1\%; regional range $1.4 \%-4.2 \%$ ) in the GLA group and 1,423 / $66,726$ (2.1\%; regional range $0.7 \%-7.7 \%)$ in the NEU group. Baseline patient and disease characteristics are shown in Table 1.

\section{Insulin and OGLD Exposure}

In the GLA group, the starting mean (SD) total biphasic insulin aspart 30 dose was 0.50 $(0.21) \mathrm{U} / \mathrm{kg}(n=1,352)$ and at 24 weeks was $0.59(0.26) \mathrm{U} / \mathrm{kg} \quad(n=1,066)$. In the NEU group, the starting total biphasic insulin aspart 30 dose was $0.51(0.22) \mathrm{U} / \mathrm{kg}(n=1,396)$ and at 24 weeks was $0.60(0.25) \mathrm{U} / \mathrm{kg}(n=1,172)$.
In the GLA group, most patients received twice daily biphasic insulin aspart 30 at baseline (86.0\%) and after 24 weeks (82.6\%). Other injection frequencies at baseline and week 24 , respectively, were once daily $(9.5 \%$ and $7.6 \%), 3$ times daily (4.4\% and $9.0 \%)$, and more than 3 times daily (0.1\% and $0.8 \%)$. Similarly, in the NEU group, most patients received twice daily biphasic insulin aspart 30 at baseline (81.9\%) and after 24 weeks (75.8\%). Other injection frequencies at baseline and week 24, respectively, were once daily $(9.0 \%$ and $8.7 \%)$, 3 times daily (9.0\% and $14.3 \%)$ and more than 3 times daily ( $0.1 \%$ and $1.3 \%)$.

The most frequently prescribed OGLDs were metformin and sulfonylurea. In the GLA group 916 of 1,274 (71.9\%) patients were receiving metformin before entering the study and this increased to 768 of $939(81.8 \%)$ after 24 weeks of biphasic insulin aspart 30 treatment. In the NEU group 860 of 1,100 (78.2\%) were receiving metformin before entering the study and this increased to 773 of 888 (87.0\%) after 24 weeks of biphasic insulin aspart 30 treatment. In the GLA group 794 of 1,274 (62.3\%) patients were receiving sulfonylurea before entering the study and this dropped to 307 of 939 (32.7\%) after 24 weeks of biphasic insulin aspart 30 treatment. In the NEU group 665 of 1,100 (60.5\%) patients were receiving sulfonylurea before entering the study and this dropped to 206 of 888 (23.2\%) patients after 24 weeks of biphasic insulin aspart 30 treatment.

\section{Safety Measures}

\section{Hypoglycemia}

After 24 weeks of receiving biphasic insulin aspart 30, the proportion of participants experiencing hypoglycemia events, major hypoglycemia, and nocturnal hypoglycemia significantly decreased from baseline in the 
Table 1 Baseline patient and disease characteristics by pre-study basal insulin group

\begin{tabular}{lll}
\hline & $\begin{array}{l}\text { GLA } \\
\text { group }\end{array}$ & $\begin{array}{l}\text { NEU } \\
\text { group }\end{array}$ \\
\hline Mean (SD) age (year) $^{\mathrm{a}}$ & $56.2(12.2)$ & $58.1(11.3)$ \\
${\text { Male, } n(\%)^{\mathrm{b}}}^{\text {Mean (SD) weight }(\mathrm{kg})^{\mathrm{c}}}$ & $705(50.6)$ & $660(46.4)$ \\
Mean (SD) BMI $\left(\mathrm{kg} / \mathrm{m}^{2}\right)^{\mathrm{d}}$ & $27.4(5.4)$ & $28.1(5.6)$ \\
$\begin{array}{l}\text { Mean (SD) diabetes duration } \\
(\text { year) }\end{array}$ & $10.3(6.3)$ & $11.4(6.9)$ \\
$\begin{array}{c}\text { Mean (SD) pre-switch insulin } \\
\text { dose (U/kg) }\end{array}$ & $0.36(0.19)$ & $0.46(0.26)$ \\
\hline
\end{tabular}

Due to the non-interventional nature of this study, not all baseline data were recorded and some patients were lost to follow-up

GLA insulin glargine group, $N E U$ insulin neutral protamine Hagedorn group

${ }^{\mathrm{a}} n=1,381$ GLA; $n=1,402 \mathrm{NEU}$

b $n=1,394$ GLA; $n=1,423 \mathrm{NEU}$

c $n=1,352$ GLA; $n=1,397 \mathrm{NEU}$

d $n=1,291$ GLA; $n=1,318$ NEU

e $n=1,368$ GLA; $n=1,409 \mathrm{NEU}$

${ }^{\mathrm{f}} n=1,352$ GLA; $n=1,397 \mathrm{NEU}$

NEU and GLA groups $(p<0.05$; Table 2$)$. There was no indication that the proportion of patients experiencing a hypoglycemia event at baseline and at 24 weeks was higher in those taking sulfonylureas compared with those who were not taking sulfonylureas (Table 2).

\section{SADRs}

Two SADRs were recorded that were probably due to biphasic insulin aspart 30: one hypoglycemia unconsciousness event in the GLA group and one hypoglycemia event in the NEU group.

\section{Body Weight}

There was a statistically significant $(p<0.01)$ weight gain $(0.3 \mathrm{~kg})$ after 24 weeks of biphasic aspart 30 in the GLA group, but no significant weight change in the NEU group (Table 2).

\section{Systolic Blood Pressure}

There was a statistically significant $(p<0.001)$ reduction in systolic blood pressure after 24 weeks of biphasic aspart 30 in both the GLA group and NEU group (Table 2).

\section{Effectiveness Measures}

\section{Glycemic Measures}

After 24 weeks of treatment with biphasic insulin aspart 30, both groups showed statistically significant improvements from baseline in $\mathrm{HbA}_{1 \mathrm{c}}$ (Fig. 1). Specifically there was a mean $1.9 \%(21 \mathrm{mmol} / \mathrm{mol})$ and $2.0 \%$ (22 mmol/mol) improvement in $\mathrm{HbA}_{1 \mathrm{c}}$ in the GLA and NEU group, respectively (Table 3) There were also significant improvements in FPG and PPG (postbreakfast, post-lunch, and post-dinner) levels $(p<0.001$; Table 3$)$.

At baseline in the NEU group, 4/74 (5.4\%), $29 / 954(3.0 \%)$ and $4 / 108$ (3.7\%) individuals who were switched to once-daily, twice-daily, or three or more daily injections of biphasic insulin aspart 30, respectively, had achieved glycemic control targets $\left(\mathrm{HbA}_{1 \mathrm{c}}<7 \%\right.$; $<53 \mathrm{mmol} / \mathrm{mol}$ ). After 24 weeks of biphasic insulin aspart 30, in the NEU group 15/64 (23.4\%), 263/851 (30.9\%), and 27/93 (29.0\%) achieved glycemic control targets, respectively.

At baseline in the GLA group, 10/91 (11.0\%), 29/1,041 (2.8\%), and 0/55 (0.0\%) individuals who were switched to once-daily, twice-daily, or three or more daily injections of biphasic insulin aspart 30, respectively, had reached glycemic control targets. After 24 weeks of biphasic insulin aspart 30 in the GLA group, $17 / 76$ (22.4\%), 188/875 (21.5\%) and 14/49 (28.6\%) individuals achieved glycemic control targets, respectively. 
Table 2 Safety outcomes before and after 24 weeks of treatment with biphasic insulin aspart 30

\begin{tabular}{|c|c|c|c|c|c|c|}
\hline \multirow[t]{3}{*}{ Measurement } & \multicolumn{3}{|l|}{ GLA group } & \multicolumn{3}{|l|}{ NEU group } \\
\hline & \multicolumn{6}{|c|}{ \% Patients with at least one event (event/person-year) } \\
\hline & $\begin{array}{l}\text { Baseline } \\
(n=1,395)\end{array}$ & $\begin{array}{l}24 \text { weeks } \\
(n=1,200)\end{array}$ & $p$ & $\begin{array}{l}\text { Baseline } \\
(n=1,423)\end{array}$ & $\begin{array}{l}24 \text { weeks } \\
(n=1,271)\end{array}$ & $p$ \\
\hline Hypoglycemia (overall) & $12.3(3.10)$ & $9.9(2.98)$ & $<0.05$ & $15.5(6.09)$ & $9.7(2.76)$ & $<0.001$ \\
\hline Hypoglycemia (major) & $1.2(0.16)$ & $0.08(0.01)$ & $<0.001$ & $2.5(0.62)$ & $0.08(0.01)$ & $<0.001$ \\
\hline Hypoglycemia (nocturnal) & $5.4(1.03)$ & $3.9(0.88)$ & $<0.05$ & $7.2(1.97)$ & $3.5(0.59)$ & $<0.001$ \\
\hline $\begin{array}{l}\text { Hypoglycemia (overall) } \\
\text { sulfonylurea }^{\mathrm{a}}\end{array}$ & $11.2(3.06)$ & $5.5(1.61)$ & & $15.3(5.88)$ & $3.9(1.07)$ & \\
\hline $\begin{array}{l}\text { Hypoglycemia (overall) } \\
\text { non-sulfonylurea }^{\mathrm{b}}\end{array}$ & $13.6(3.16)$ & $11.4(3.45)$ & & $15.7(6.28)$ & $10.8(3.09)$ & \\
\hline Mean body weight, $\mathrm{kg}(\mathrm{SD})^{\mathrm{c}}$ & $73.2(14.7)$ & $73.5(14.3)$ & $<0.01$ & $75.4(16.6)$ & $75.2(16.4)$ & 0.22 \\
\hline $\begin{array}{l}\text { Mean }(\mathrm{SD}) \text { systolic blood } \\
\text { pressure, } \mathrm{mmHg}^{\mathrm{d}}\end{array}$ & $134.0(18.4)$ & $129.1(14.7)$ & $<0.001$ & $137.7(16.8)$ & $129.4(13.7)$ & $<0.001$ \\
\hline
\end{tabular}

Due to the non-interventional nature of this study, some patients were lost to follow-up. $p$ calculated using McNemar's test on incidence of hypoglycemia at baseline vs. 24 weeks

$G L A$ insulin glargine group, $N E U$ insulin neutral protamine Hagedorn group

a $n=794$ GLA baseline, $n=307$ GLA 24 weeks; $n=665$ NEU baseline, $n=206$ NEU 24 weeks

b $n=601$ GLA baseline, $n=893$ GLA 24 weeks; $n=758$ NEU baseline, $n=1,065$ NEU 24 weeks

c $n=1,052$ GLA baseline and 24 weeks; $n=1,167$ NEU baseline and 24 weeks

d $n=1,031$ GLA baseline and 24 weeks; $n=1,140$ NEU baseline and 24 weeks

\section{HRQoL}

There was statistically significant $(p<0.001)$ improvement in VAS scores after 24 weeks in both groups (Table 3). For both groups, there was significant improvement in all five parameters of EQ-5D (no problem performing usual activities, freedom from anxiety/ depression; no problem walking; no pain or discomfort and no problems with self-care; $p<0.001)$.

\section{DISCUSSION}

This sub-analysis from the $\mathrm{A}_{1}$ chieve study showed that switching to therapy with biphasic insulin aspart 30 ( \pm OGLDs) from basal insulin regimens under routine clinical

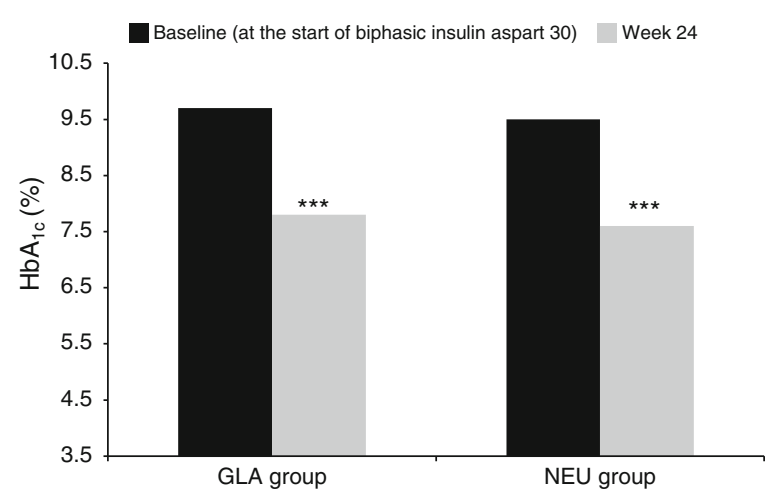

Fig. 1 Mean plasma glycated hemoglobin among patients switching to biphasic insulin aspart 30 from insulin glargine- or neutral protamine Hagedorn-based basal insulin regimens. GLA insulin glargine group, $H b A_{1 c}$ glycated hemoglobin, $N E U$ neutral protamine Hagedorn group. ${ }^{* * *} p<0.001$ vs. baseline $n=894$ GLA baseline and 24 weeks; $n=913$ NEU baseline and 24 weeks 
Table 3 Change in effectiveness outcomes after 24 weeks of treatment with biphasic insulin aspart 30

\begin{tabular}{|c|c|c|c|c|c|c|c|c|}
\hline & \multicolumn{4}{|c|}{ GLA group } & \multicolumn{4}{|c|}{ NEU group } \\
\hline & $\bar{n}$ & Baseline & $\begin{array}{l}\text { Change at } \\
24 \text { weeks }\end{array}$ & $p$ & $\bar{n}$ & Baseline & $\begin{array}{l}\text { Change at } \\
24 \text { weeks }\end{array}$ & $p$ \\
\hline $\mathrm{HbA}_{1 \mathrm{c}} \%(\mathrm{SD})$ & 894 & $9.7(1.7)$ & $-1.9(1.7)$ & $<0.001$ & 913 & $9.5(1.6)$ & $-2.0(1.7)$ & $<0.001$ \\
\hline $\mathrm{HbA}_{1 \mathrm{c}} \mathrm{mmol}(\mathrm{SD})$ & & $83(19)$ & $-21(18)$ & & & $80(18)$ & $-21(18)$ & \\
\hline $\begin{array}{l}\text { FPG (pre-breakfast) } \mathrm{mmol} / \mathrm{l} \\
(\mathrm{SD})\end{array}$ & 956 & $10.4(3.4)$ & $-2.9(3.7)$ & $<0.001$ & 1,062 & $10.7(3.8)$ & $-3.5(3.9)$ & $<0.001$ \\
\hline $\begin{array}{l}\text { PPG (post-breakfast) mmol/l } \\
\text { (SD) }\end{array}$ & 710 & $15.0(4.2)$ & $-4.6(4.4)$ & $<0.001$ & 747 & $14.6(4.5)$ & $-5.1(5.0)$ & $<0.001$ \\
\hline PPG (post-lunch) mmol/l (sD) & 146 & $13.8(4.4)$ & $-4.5(4.5)$ & $<0.001$ & 257 & $12.5(3.5)$ & $-3.9(3.5)$ & $<0.001$ \\
\hline PPG (post-dinner) mmol/l (sD) & 127 & $13.1(3.9)$ & $-4.3(4.3)$ & $<0.001$ & 246 & $12.3(3.5)$ & $-4.0(3.6)$ & $<0.001$ \\
\hline HRQoL, VAS (SD) & 923 & $63.4(15.8)$ & $+10.3(17.2)$ & $<0.001$ & 929 & $63.3(16.4)$ & $+10.8(16.0)$ & $<0.001$ \\
\hline $\begin{array}{l}\text { No problem performing usual } \\
\text { activities, } \%\end{array}$ & 946 & 65.8 & +14.1 & $<0.001$ & 952 & 58.0 & +18.4 & $<0.001$ \\
\hline Free from anxiety/depression, $\%$ & 949 & 54.9 & +12.9 & $<0.001$ & 956 & 53.9 & +19.5 & $<0.001$ \\
\hline No problems walking, $\%$ & 949 & 64.1 & +20.3 & $<0.001$ & 958 & 59.7 & +17.9 & $<0.001$ \\
\hline No pain or discomfort, $\%$ & 949 & 49.4 & +14.7 & $<0.001$ & 956 & 46.9 & +14.8 & $<0.001$ \\
\hline No problems with self-care, $\%$ & 946 & 73.7 & +12.5 & $<0.001$ & 956 & 77.2 & +11.1 & $<0.001$ \\
\hline
\end{tabular}

Due to the non-interventional nature of this study, not all baseline data were recorded and some patients were lost to followup

FPG fasting plasma glucose, GLA insulin glargine group, $H b A 1 c$ glycated hemoglobin hemoglobin, HRQoL health-related quality of life, $N E U$ insulin neutral protamine Hagedorn group, $P P G$ post-prandial plasma glucose, $V A S$ visual analogue scale

practice led to significant improvements in blood glucose levels (as measured by $\mathrm{HbA}_{1 \mathrm{c}}$, FPG, and PPG) in patients with type 2 diabetes who had poor glycemic control. Switching to biphasic insulin aspart 30 was also well tolerated with only two serious adverse events recorded among the 2,818 participants during the 24 weeks of biphasic insulin aspart 30 treatment.

Importantly in both the NEU and GLA groups, improvement in glycemic control was achieved with a significant reduction in overall, major and nocturnal hypoglycemia during treatment with biphasic insulin aspart 30 ( \pm OGLDs) relative to baseline. Despite the reduction in sulfonylurea use in both groups after 24 weeks compared with baseline, there was no indication that the proportion of patients experiencing hypoglycemia events was higher in those taking sulfonylureas compared with those not taking sulfonylureas. Therefore, the reduction in hypoglycemia events is likely to be due to the optimized treatment with biphasic insulin aspart 30. This finding would be consistent with previous studies that showed significant reductions in hypoglycemia after patients were switched from NPH insulin to biphasic insulin aspart 30 $[1,14]$. Others have reported that improved 
hyperglycemia and a lower proportion of people experiencing hypoglycemia can be achieved and maintained in patients receiving biphasic insulin aspart 30 who have optimized their insulin dosage [15]. As there was no control arm in the study, it is not possible to determine if the placebo effect due to participation in a clinical trial had any impact on the reduced incidence of hypoglycemia.

Significant improvements in all five parameters of EQ-5D were observed in both groups after 24 weeks of biphasic insulin aspart 30. These findings are similar to those observed for the wider $A_{1}$ chieve cohort [16], and other studies have found that treatment with biphasic insulin aspart 30 significantly improved HRQoL, improved life-expectancy, and qualityadjusted life expectancy [17-19].

A combination of basal insulin and OGLDs is effective as an initial therapy in people with type 2 diabetes and poor glycemic control [20]. Basal insulins, such as insulin glargine and NPH insulin, do not target PPG fluctuations [8, 9], and, therefore, the efficacy of basal insulin begins to wane in some patients because PPG continues to rise [21]. The significant improvements in $\mathrm{HbA}_{1 \mathrm{c}}$ in this study may be linked to significant improvements in PPG after 24 weeks of biphasic aspart 30 treatment. Previous studies have shown that biphasic insulin aspart 30 may lead to significantly improved PPG control with concomitant significant improvement in $\mathrm{HbA}_{1 \mathrm{c}}$ values compared with basal insulin therapies [14, 2225]. This is an important distinction because post-prandial hyperglycemia is recognized as being harmful and the International Diabetes Federation recommends the implementation of strategies to lower PPG [26]. The control of PPG plasma levels is now recognized as a fundamental consideration in prevention of endothelial dysfunction leading to the progression to macrovascular and microvascular complications of diabetes [27, 28]. Furthermore, a joint consensus statement from the American Diabetes Association (ADA) and European Association for the Study of Diabetes (EASD) states that mealtime insulin coverage is appropriate for patients receiving basal insulin but who are experiencing significant PPG excursions (>10 mmol/l; $>180 \mathrm{mg} / \mathrm{dl}$ ) [29]. The ADA/EASD consensus also intimates that premixed insulin may be appropriate for patients who eat regularly and who may be in need of a simplified approach to glycemic control beyond basal insulin [29]

Regarding people with type 2 diabetes with poor glycemic control, intensification from basal insulins to biphasic premixed insulin aspart 30 may enable them to reach glycemic targets for longer periods [21]. The glycemic improvements in this analysis occurred in both groups of patients regardless of previous basal insulin regimen.

A statistically significant increase in weight was noted in the GLA group after 24 weeks of insulin aspart 30, which is in line with findings from other studies [30, 31]. However, it is questionable whether a mean $0.3 \mathrm{~kg}$ increase in weight after 24 weeks of insulin aspart 30 treatment is clinically important.

A limitation of the study is that it was a subanalysis of $A_{1}$ chieve with a reduction in number of participants from over 66,000 in the full study to 2,818 participants in the sub-analysis; this may have led to the risk of type II error or bias in the dataset. Also, observational studies are not randomized and are more susceptible to selection bias. For example, this sub-analysis did not control for concomitant medication or dietary intake, and some outcomes relied on self-reported information, participant recall, or diverse diaries. However, the advantage of this study is the real-world clinical setting, including 
actual practice patterns and a broader population than would be included in a randomized controlled trial. Furthermore, despite these limitations, data from this subanalysis will help to elucidate the safety and effectiveness of biphasic insulin aspart 30 in patients switching from basal insulin regimens.

\section{CONCLUSION}

Biphasic insulin aspart 30 can be a well-tolerated and effective treatment in everyday clinical practice for patients with type 2 diabetes who are poorly controlled with basal insulin treatment. Twenty-four weeks of treatment with biphasic insulin aspart 30 led to significant improvements from baseline in $\mathrm{HbA}_{1 \mathrm{c}}, \mathrm{FPG}$, and PPG levels $(p<0.001$ for all parameters). Risk of major hypoglycemia was reduced in both the GLA and NEU groups and there were significant improvements in all aspects of HRQoL as measured by EQ-5D (no problems performing usual activities, freedom from anxiety and depression, no problems walking, no pain or discomfort and no problems with self-care). Biphasic insulin aspart 30 may benefit patients with poor glycemic control on basal insulin regimens who are seeking to change treatment.

\section{ACKNOWLEDGMENTS}

The $A_{1}$ chieve study and this manuscript were funded by Novo Nordisk International Operations. Editorial assistance was provided by John Clarke, ESP Bioscience Ltd, Crowthorne, UK, funded by Novo Nordisk International Operations. Dr. Prusty is the guarantor for this article, and takes responsibility for the integrity of the work as a whole.
Conflict of interest. Jihad Haddad has acted as a speaker for Novo Nordisk, Novartis, MSD, Merck Serono, and AstraZeneca, and an advisory board member for Novo Nordisk and Merck Serono. Mohsen Khoshniatnikoo has acted as a speaker and is an advisory board member for Novo Nordisk. Youcef Benabbas has participated in advisory boards and as a consultant for Novo-Nordisk. Serdar Guler has participated in international clinical trials sponsored by Novo Nordisk. Vinay Prusty is an employee of Novo Nordisk A/S. Pradana Soewondo is an advisory board member for Novo Nordisk, Sanofi-Aventis, and Novartis.

Compliance with ethics guidelines. All study participants signed informed consent forms and were free to withdraw from the study at any time. The study was conducted in accordance with the Declaration of Helsinki of 1964, as revised in 2008, and guidelines for good pharmacoepidemiology practice.

Open Access. This article is distributed under the terms of the Creative Commons Attribution Noncommercial License which permits any noncommercial use, distribution, and reproduction in any medium, provided the original author(s) and the source are credited.

\section{REFERENCES}

1. Jang HC, Guler S, Shestakova M, PRESENT Study Group. When glycaemic targets can no longer be achieved with basal insulin in type 2 diabetes, can simple intensification with a modern premixed insulin help? Results from a subanalysis of the PRESENT study. Int J Clin Pract. 2008;62: 1013-8.

2. Giugliano D, Maiorino MI, Bellastella G, Chiodini P, Ceriello A, Esposito K. Efficacy of insulin analogs in achieving the hemoglobin $\mathrm{A}_{1 \mathrm{c}}$ target of $<7 \%$ in type 2 diabetes: meta-analysis of randomized controlled trials. Diabetes Care. 2011;34:510-7. 
3. Qayyum R, Bolen S, Maruthur N, et al. Systematic review: comparative effectiveness and safety of premixed insulin analogues in type 2 diabetes. Ann Intern Med. 2008;149:549-59.

4. Woerle HJ, Neumann C, Zschau S, et al. Impact of fasting and postprandial glycemia on overall glycemic control in type 2 diabetes Importance of postprandial glycemia to achieve target $\mathrm{HbA}_{1 \mathrm{c}}$ levels. Diabetes Res Clin Pract. 2007;77:280-5.

5. Hanefeld M, Koehler C, Schaper F, Fuecker K, Henkel E, Temelkova-Kurktschiev T. Postprandial plasma glucose is an independent risk factor for increased carotid intima-media thickness in nondiabetic individuals. Atherosclerosis. 1999;144: 229-35.

6. Levitan EB, Song Y, Ford ES, Liu S. Is nondiabetic hyperglycemia a risk factor for cardiovascular disease? A meta-analysis of prospective studies. Arch Intern Med. 2004;164:2147-55.

7. Shiraiwa $\mathrm{T}$, Kaneto $\mathrm{H}$, Miyatsuka $\mathrm{T}$, et al. Postprandial hyperglycemia is a better predictor of the progression of diabetic retinopathy than HbA1c in Japanese type 2 diabetic patients. Diabetes Care. 2005;28:2806-7.

8. Hartman I. Insulin analogs: impact on treatment success, satisfaction, quality of life, and adherence. Clin Med Res. 2008;6:54-67.

9. Nelson SE. Detemir as a once-daily basal insulin in type 2 diabetes. Clin Pharmacol. 2011;3:27-37.

10. Halimi S, Raskin P, Liebl A, Kawamori R, Fulcher G, Yan G. Efficacy of biphasic insulin aspart in patients with type 2 diabetes. Clin Ther. 2005;27(Suppl B):S57-74.

11. Home $P$, Naggar NE, Khamseh $M$, et al. An observational non-interventional study of people with diabetes beginning or changed to insulin analogue therapy in non-Western countries: the $\mathrm{A}_{1}$ chieve study. Diabetes Res Clin Pract. 2011;94: 352-63.

12. World Medical Association. Declaration of Helsinki-ethical principles for medical research involving human subjects 2008. http://www. riip-influenza.org/wp-content/uploads/2011/08/ Helsinki-2008-EN.pdf. Accessed May 1, 2013.

13. International Society for Pharmacoepidemiology. Guidelines for good pharmacoepidemiology practices (GPP). Revision 2, April 2007.

14. Gumprecht J, Benroubi M, Borzi V, et al. Intensification to biphasic insulin aspart 30/70 (BIAsp 30, NovoMix 30) can improve glycaemic control in patients treated with basal insulins: a subgroup analysis of the IMPROVE observational study. Int J Clin Pract. 2009;63:966-72.

15. Trippe BS, Shepherd MD, Coulter FC, et al. Efficacy and safety of biphasic insulin aspart 70/30 in type 2 diabetes patients of different race or ethnicity (INITIATE plus trial). Curr Med Res Opin. 2012;28:1203-11.

16. Shah S, Zilov A, Malek R, Soewondo P, Bech O, Litwak L. Improvements in quality of life associated with insulin analogue therapies in people with type 2 diabetes: results from the $A_{1}$ chieve observational study. Diabetes Res Clin Pract. 2011;94:364-70.

17. Ali M, White J, Lee $\mathrm{CH}$, et al. Therapy conversion to biphasic insulin aspart 30 improves long-term outcomes and reduces the costs of type 2 diabetes in Saudi Arabia. J Med Econ. 2008;11:651-70.

18. Esteghamati A, Rajabian R, Amini M, et al. The safety and efficacy of biphasic insulin aspart 30 (BIAsp 30) in Iranians with type 2 diabetes: an open-label, non-randomised, multi-centre observational study-the Iran subgroup of the IMPROVE study. Endokrynol Pol. 2010;61:364-70.

19. Hassan MI, Aamir AH, Miyan Z, Siddiqui LA, Qureshi MS, Shaikh MZ. Safety and effectiveness of biphasic insulin aspart 30 (Biasp 30) in people with type 2 diabetes mellitus in the pakistani population: results from the A1chieve study. J Pak Med Assoc. 2012;62:929-36.

20. Dailey G. New strategies for basal insulin treatment in type 2 diabetes mellitus. Clin Ther. 2004;26: 889-901.

21. Unnikrishnan AG, Tibaldi J, Hadley-Brown M, et al. Practical guidance on intensification of insulin therapy with BIAsp 30: a consensus statement. Int J Clin Pract. 2009;63:1571-7.

22. Christiansen JS, Vaz JA, Metelko Z, Bogoev M, Dedov I. Twice daily biphasic insulin aspart improves postprandial glycaemic control more effectively than twice daily NPH insulin, with low risk of hypoglycaemia, in patients with type 2 diabetes. Diabetes Obes Metab. 2003;5:446-54.

23. Hermansen $\mathrm{K}$, Colombo M, Storgaard H, Østergaard A, Kolendorf K, Madsbad S. Improved postprandial glycemic control with biphasic insulin aspart relative to biphasic insulin lispro and biphasic human insulin in patients with type 2 diabetes. Diabetes Care. 2002;25:883-8.

24. Jang HC, Lee SR, Vaz JA. Biphasic insulin aspart 30 in the treatment of elderly patients with type 2 diabetes: a subgroup analysis of the PRESENT Korea NovoMix study. Diabetes Obes Metab. 2009;11: 20-6. 
25. Valensi $\mathrm{P}$, Benroubi $\mathrm{M}$, Borzi $\mathrm{V}$, et al. Initiating insulin therapy with, or switching existing insulin therapy to, biphasic insulin aspart 30/70 (NovoMix 30) in routine care: safety and effectiveness in patients with type 2 diabetes in the IMPROVE observational study. Int J Clin Pract. 2009;63: 522-31.

26. Ceriello A, Colagiuri S. International Diabetes Federation guideline for management of postmeal glucose: a review of recommendations. Diabet Med. 2008;25:1151-6.

27. Ceriello A, Cavarape A, Martinelli L, et al. The postprandial state in type 2 diabetes and endothelial dysfunction: effects of insulin aspart. Diabet Med. 2004;21:171-5.

28. International Diabetes Federation. Guideline for management of postmeal glucose in diabetes. 2011. http://www.idf.org/sites/default/files/postmeal\%20 glucose\%20guidelines.pdf. Accessed August 30, 2012.

29. Inzucchi SE, Bergenstal RM, Buse JB, et al. Management of hyperglycemia in type 2 diabetes: a patient-centered approach: position statement of the American Diabetes Association (ADA) and the European Association for the Study of Diabetes (EASD). Diabetes Care. 2012;35:1364-79.

30. Raskin P, Allen E, Hollander $\mathrm{P}$, et al. Initiating insulin therapy in type 2 Diabetes: a comparison of biphasic and basal insulin analogs. Diabetes Care. 2005;28:260-5.

31. Raskin PR, Hollander PA, Lewin A, et al. Basal insulin or premix analogue therapy in type 2 diabetes patients. Eur J Intern Med. 2007;18:56-62. 